\title{
Problems and Solutions of Consumers' Rights Protection under Micro-commerce Model
}

\author{
$\mathrm{Fu}$ Qiqi \\ Northeast Agricultural University \\ Harbin, China 150036
}

\begin{abstract}
This paper outlines some basic problems and solutions and discusses some related theoretical and practical issues related to consumers' rights protection under microcommerce model. We also compare the characteristics of traditional e-commerce and micro-commerce. We find that micro-commerce model is developed on the basis of mature internet technology. Our results show that although microcommerce model infringes consumers' rights to safety, information, fair dealing, claim and rescission. But $I$ believe that consumers' rights will get better protection under microcommerce model. Our studies indicate that the emergence of micro-commerce will boost the development of low-end economy.
\end{abstract}

Keywords-Micro-commerce; Consumers; Rights protection; Solution

\section{INTRODUCTION}

\section{A. Definition of micro-commerce}

There is no professional definition for what is microcommerce. One view is that it means using social communication software-WeChat to publicize products, pictures, prices in WeChat's circle of friends, etc, and pay for them through WeChat's red packets, WeChat transfer and Alipay transfer. Another point of view is that micro-commerce refers to a business mode that deals with products such as WeChat, QQ, micro-blog and other social communication software, releasing products, pictures, prices, and then pay for them through WeChat, Alipay or bank card payment. Through comparison, we can see that the former defines microcommerce in a narrow aspect, while the latter defines it in a broad aspect. Based on the investigation of the characteristics of micro-commerce trading mode, this paper adopts the second view, that is, to define micro-commerce in a broad aspect, and to bring more transactions which are carried out with the help of mobile social software platform into the scope of microcommerce.

\section{B. Characteristics of micro-commerce}

As a new type of e-commerce, micro-commerce is based on the mature development of traditional e-commerce. Compared with traditional e-commerce such as Taobao, Jingdong and other shopping modes, micro-commerce has its own unique characteristics. Firstly, the trading activities under the microcommerce model are mainly carried out among friends. Microbusinessmen form friendship relationship with their trading partners by adding friends and concerns in their registered social communication software, which can be called an acquaintance economy. Secondly, the trading activities under the micro-commerce model are carried out in a closed environment. In the process of transaction, the seller provides product information, the buyer pays the price, then the seller delivers the goods, and finally they finish the transaction. In this process, the transaction between the two sides is a one-way transaction, so the transaction between the two sides has strong privacy and closeness. Thirdly, there is a gradability between micro-merchants. On the one hand, micro-businessmen gain profits by selling products, on the other hand, microbusinessmen gain profits by continuously recruiting agents, such as first-level agents, second-level agents, etc. In addition, lower-level agents purchase goods in batches from higher-level agents, and higher-level agents get high income, and the ultimate result is that consumers at the bottom need to pay for higher prices.

\section{PROBLEMS OF CONSUMER RIGHTS PROTECTION UNDER MICRO-COMMERCE MODEL}

Consumers refer to individuals who purchase, use goods or receive services to meet their life needs. The products sold under the micro-commerce model are mostly cosmetics, clothing, health care products and so on, which mostly meet the needs of personal life. Therefore, the buyer in the microcommerce model should belong to consumers. In the following, we discuss the problems of consumer rights protection under the micro-commerce model from different aspects of rights.

\section{A. Infringement on Consumers' Right to Safety}

The right to safety refers that consumers inviolate their personal and property security when they purchase goods and receive services. On the one hand, micro-businessmen only inform their product information by providing pictures, videos and effective comparisons of related products on social communication platforms, and this information is likely to be produced by designing. Therefore, consumers only rely on these surficial information to consume. The risk of personal injury caused by unqualified quality and fake products, such as toxic mask events in real life, they all infringe on consumers right to personal safety. On the other hand, the microcommerce mode is based on the consumers' purchase information, which is the way consumers pay the goods, and consumers pay the payment mainly through WeChat's red 
packets, WeChat transfer, Alipay transfer, bank card transfer and then sellers post goods. Sellers often do not post goods after getting money. At this time, consumers lose money in vain and infringe on the property rights of consumers. When consumers pay for the goods in private ways, microbusinessmen are very easy to use hacker technology to invade the financial accounts of consumers, then stealing and canceling the funds of consumers and infringing Consumers' right to property security.

\section{B. Infringement on Consumers' Right to Information}

The right to information refers that consumers should know the real situation of goods they buy or use and services they receive. These facts include the price, origin, producer, date of production, certificate of conformity and all other information about goods or services. Under the micro-commerce model, micro-businesses do not need to use spokesmen to advertise their products. Usually, micro-businesses organize their own language, take pictures, shoot videos and publish them on friends circles, and other social communication platforms. In essence, micro-businesses make their own advertisements and publish them. Therefore, micro-businesses are likely to make false advertisements and make false representations of the performance of goods, certificates of conformity, etc., and even make false pictures of the best-selling products by technical means. In addition, due to the existence of layers of agents, the prices of goods vary because of the different levels of agents, and the selling prices are far from the actual value of goods. Causing consumers to fall into the wrong understanding of the basic information of commodities and infringing consumers' right to information.

\section{Infringement on Consumer's Right to Fair Dealing}

Fair dealing right refers that consumers enjoy fair and reasonable market exchange when they purchase goods or receive services. It means that the rights and obligations of micro-merchants and consumers are equal and equivalent. Firstly, under the micro-commerce model, because of their great privacy, micro-businesses and consumers often conclude unfair contracts to consumers in advance, and even have compellent contracts and overlord clauses. Consumers have no right to modify the unfair and non-standard contracts. Secondly, due to the way that consumers pay for the goods first and sellers deliver the goods, it often occurs that the micromerchants fail to deliver the goods after the consumers fulfill the obligation of paying for the goods. Thirdly, if the goods are defective and need to be returned or exchanged, due to the lack of third party guarantee, the initiative of returning or exchanging goods is entirely in the hands of micro-merchants, who may be idle in fulfilling or not fulfilling the obligation. All of the above have seriously infringed the fair dealing rights of consumers.

\section{Infringement on Consumer's Right of Claim}

Claim right refers that consumers should obtain compensation according to law for personal and property damage caused by purchasing, using commodities or receiving services. For the personal and property damage caused to consumers by the defects of commodities, the possibility of consumers getting compensation is very small. Firstly, due to the virtuality of the network environment, when some consumers make compensation claims to micro-businessmen through social communication software, micro-businessmen evade consumers by blackning, deleting or canceling their concerns. At this time, it is difficult for consumers to contact the compensation subject. Secondly, it is difficult to confirm the identity of micro-businessmen. Many micro-businessmen only register an account on social software, but many software do not adopt real-name system. At this time, once personal and property damage occurs to consumers and they claim compensation, it is difficult to find a real and definite compensation subject. Thirdly, when consumers resolve disputes through litigation, they must choose a court with jurisdiction. However, the subject of micro-commerce is fictitious. The choice of jurisdiction court will consume a lot of time and energy of consumers in a disadvantaged position, and the smooth progress of litigation procedure is based on real and legitimate evidence. Once consumers delete transaction records and transfer records, they lose the key evidence of winning the lawsuit. It is even more difficult for consumers to obtain compensation.

\section{E. Infringement on Consumer's Right of Rescission}

The right of rescission refers that consumers have the right to return goods within seven days from the date of receipt of the goods when they purchase goods by means of remote shopping, such as internet, without explaining the reasons for the return. This is a special protection given to consumers by the new Consumer Rights and Interests Protection Law of our country based on the vulnerable position of consumers and the risks in online shopping. However, the right of rescission is mainly aimed at traditional electronic commerce. The subject of micro-commerce is not explicitly included in the scope of the object of consumer's right by law. Moreover, from the above discussion, we can know that when consumers buy defective and defective goods, the right to return and exchange goods and obtain compensation can not be effectively guaranteed. It is a fantasy for consumers to return goods and exercise the right of rescission without the existence of defective and defective products. Therefore, consumer's right of rescission is harder to realize under the micro-commerce model.

\section{SOLUTIONS TO THE PROBLEMS OF CONSUMERS' RightS PROTECTION UNDER THE MICRO-COMMERCE MODEL}

\section{A. Perfecting relevant legislation}

Before, there was no special legal regulation on traditional e-commerce. The regulation on traditional e-commerce was mainly scattered in other relevant laws and relevant documents issued by the state, such as Consumer Rights Protection Law, Product Quality Law and so on. There was a lack of specialization for micro-commerce, which is a new type of ecommerce. The regulation of micro-merchants by legal norms leads to more and more acute problems such as unclear subject and unclear responsibility of micro-merchants. However, on August 31, 2018, China passed the Electronic Commerce Law and would implement it on January 1, 2019. This is the first 
special legislation on electronic commerce in China, which will have a great impact on electronic commerce. Moreover, the Electronic Commerce Law brings micro-commerce, a new type of electronic commerce, into the scope of regulation.

Firstly, the identity of micro-businessmen is clarified. Article 9 of the Electronic Commerce Law stipulates that ecommerce operators include e-commerce platform operators, platform operators and e-commerce operators who sell goods or provide services through self-built websites or other network services. Article 9 clarifies that micro-businessmen belong to ecommerce operators, eliminating the embarrassing situation of micro-businessmen in "grey zone". Secondly, the market access threshold should be set. Article 10 of the Electronic Commerce Law stipulates that the operators of electronic commerce shall register the market subjects according to law. Compared with the previous zero threshold phenomenon in micro-commerce operation, this regulation sets a threshold for micro-business to engage in selling activities. These are the direct provisions on micro-commerce in the Electronic Commerce Law, and are the progress in the legislation of electronic commerce in our country.

However, there are still some deficiencies in the provisions of the Electronic Commerce Law on micro-commerce, which need to be further improved. Firstly, Article 38 of the Electronic Commerce Law stipulates that the operators of electronic commerce platforms sell goods or services that do not meet the requirements of personal and property security. If the operators of electronic commerce platforms are at fault, they shall bear joint and several liabilities with the operators of the platforms. This regulation increases the responsibilities of the operators of electronic commerce platforms, which mainly includes Taobao, Tianmao and other traditional e-commerce, the social communication platform for micro-commerce is not included. Therefore, I think we can further develop the corresponding legal norms, requiring social communication platforms to take corresponding responsibilities in the case of fault, so as to promote social communication platforms to supervise micro-commerce activities. Secondly, in the process of dealing with disputes between the two parties, there are often cases of deletion, tampering and forgery of transaction records, which lead to difficulties in proof. At this time, it can be stipulated that both parties can obtain evidence by requesting original data from social communication platforms under certain conditions. At this time, social communication platforms bear certain obligation to provide evidence. Thirdly, with the vigorous development of e-commerce, most of users' personal information is collected and used in e-commerce activities. There are also cases of illegal access to and use of consumers' personal information by micro-businessmen. However, the protection of personal information is not stipulated in the E-commerce Law. Therefore, the Electronic Commerce Law should strengthen the protection of personal information and clarify the content and purpose of microbusinesses explicit collection and utilization of information to consumers. Fourthly, the Electronic Commerce Law clearly stipulates the subject of E-commerce, not including logistics service providers. Besides the self-built self-logistics system of the platform, logistics service providers also have independent logistics service providers, while micro-businessmen mostly use independent logistics service providers, and they have become e-commerce transaction routines. Although they are in the auxiliary position in the transaction, it does not affect them to become the main body of e-commerce together with microbusinessmen. Therefore, I think that the Electronic Commerce Law should expand the subject of e-commerce and include the service providers of logistics into the scope of e-commerce operators.

From the above content, we can know that the formulation of the Electronic Commerce Law is of great significance to the healthy development of micro-commerce. However, the provisions of the Electronic Commerce Law on microcommerce and other new types of e-commerce need to be further refined and precise, and it still need the continuous improvement of legislative technology.

\section{B. Strengthening their own construction}

1.Micro-businessmen should strengthen their own credit construction and cultivate their own credit consciousness. Our country implements market economy. Market economy is essentially credit economy. An enterprise without credit is difficult to survive in market economy and will be eliminated under the system of eliminating the fittest. Therefore, microbusinessmen must not give up their long-term interests only for the present insignificant interests, but also constantly strengthen their own credit construction, and donnot touch the bottom line of the law, resolutely safeguard the interests of consumers, win more potential customers for themselves, step by step to become strong.

2.Consumers should strengthen their awareness of vigilance and rights protection. When consumers consume, they must have in-depth understanding and investigation of commodities and micro-businesses, and trade on a reliable basis. They must not trade at will because of the low price. In addition, consumers should do a good job of preserving evidence in the process of trading by screenshots or retaining transaction records. The transaction information between depositors and micro-businessmen as well as the related information of microbusinessmen provide evidence for their possible future rights protection. At the same time, consumers should strengthen their awareness of safeguarding their rights. They should not give up their rights because of close relations and indulge the irregular and illegal trading behavior of micro-businessmen.

\section{Perfecting relief mechanism}

The improvement of relief mechanism provides more convenient ways for consumers to protect their rights and reduce the cost of protecting their rights. This paper mainly improves relief mechanism from three aspects: the rebuttal of burden of proof, the intervention of third-party payment platform and diversified ways of dispute resolution.

The system of rebuttal of burden of proof shall be implemented. In view of the great discount of consumers' right to information in the micro-commerce mode, the information they have is limited to the pictures or videos of the products provided by the micro-commerce. They may not know anything about other information, such as the specific information of the goods, the relevant information of the 
micro-commerce and the credit information of the microcommerce. It is unfair for weak consumers to provide evidence, which makes it very difficult for consumers to defend their rights. Therefore, the rebuttal of burden of proof system can be implemented under the micro-commerce model, and the strong micro-commerce can bear the adverse consequences of the impossibility of proof.

Implement the third-party payment platform intervention system. Under the micro-commerce model, consumers pay for goods directly by means of transferring money to microbusinesses and sending red packages, then micro-businesses deliver goods to consumers after receiving payment. This can easily lead to consumers receiving defective and defective goods, micro-businesses fail to perform or neglect to fulfill their obligations of refund, exchange or compensation based on the payment they have received. For the infringement of consumers' rights, we can use Taobao, Tianmao, Jingdong and other traditional e-commerce payment methods for reference and introduce a third-party payment platform. Consumers firstly pay the money to a third-party, and then confirm the receipt when they are satisfied with the goods received and inspected. The payment is transferred from the third-party to the micro-businessmen. The intervention of third-party payment platform will exert certain pressure on microbusinessmen to reduce the sales of defective and defective products.

We should adopt a pluralistic approach to dispute resolution. Litigation is the last line of defense to achieve fairness and justice, but ordinary litigation procedures need to consume a larger time and financial costs, while the disputed object amount under micro-commerce mode is generally small, consumers may lose more than what they gain by using ordinary litigation procedures, at this time, small litigation procedures can be introduced to save consumers' time and financial costs. In addition, because of the particularity of micro-commerce transaction objects, most consumers are reluctant to go through litigation procedures. At this time, we can establish a system of mediation and arbitration that is conducive to consumers, such as online or remote dispute resolution, to strengthen communication between the two sides and promote resolution of dispute. To sum up, we should establish a way of disputing resolution that integrates mediation, arbitration and litigation.

\section{SUMMARY}

The micro-commerce model really facilitates our life, but it cannot exclude the existence of violations of consumers' rights, so we still have a long way to go.

\section{REFERENCES}

[1] Dong Biao and Li Renyu. The logical basis and system design of micro regulation in the Internet + era [J]. Law Journal, 2016, (6).

[2] Yi Ling. Research on the Protection of Consumers' Rights and Interests in the Dimension of Online Shopping [J]. Hebei Law, 2016, (6).

[3] Hou Huaixia, Zhang Huiping. Research on Legal Issues of Market Regulation [M]. Shanghai: Fudan University Press, 2011.202-280.

[4] Tang Xianfeng. Legal Practice of Electronic Commerce [M]. Beijing: Tsinghua University Press, 2014.124-156.

[5] Wang Siyuan. On the Safeguard Obligation of Network Operators [J]. Contemporary Law, 2017, (1).

[6] Zuo Limin. The countermeasures to strengthen the supervision of microbusiness transactions according to law - from the perspective of microbusiness status [J]. Journal of Zhongbei University, 2016, 32 (1).

[7] Yang Qiang, Shen Yachen. Research on the influence of micro-business information source characteristics on consumers' purchase intention [J]. Journal of Dalian University of Technology, 2017, 38 (2).

[8] Yong Qixiu. Reasonable Path of Consumer Rights Protection under Micro-Business Model [D]. Lanzhou University, 2018.

[9] Liu Renrui. On the Development of Micro-Commerce in China and Legal Supervision [D]. Hunan University, 2016. 